\section{Extracorporeal membrane oxygenation}

EDITOR,-The need for facilities to provide extracorporeal membrane oxygenation (ECMO) for the newborn is as yet undetermined in the UK. To estimate the number of babies who may be candidates for this form of neonatal intensive care, we carried out a prospective study in the four Thames regional health authorities (June-November 1991) and the Oxford Regional Health Authority (November 1991-April 1992) at a time when ECMO was generally unavailable. A baby was considered to be a potential candidate for ECMO as an alternative to conventional intensive care if the fractional inspired oxygen was $>0.90$ for more than six hours with a preductal oxygen tension $\left(\mathrm{PaO}_{2}\right)<5.3 \mathrm{kPa}$ $(<40 \mathrm{~mm} \mathrm{Hg})$. Babies were not included in the monthly returns if any of the following criteria were present: cyanotic congenital heart disease, intracranial haemorrhage, gestational age $<34$ weeks, birth weight $<2000 \mathrm{~g}$, artificial ventilation $>10$ days, bleeding diathesis, severe congenital abnormality, chromosome abnormality, or severe hypoxic ischaemic encephalopathy.

Sixteen neonatal units capable of providing intensive care in the four Thames regional health authorities and 10 in the Oxford region returned complete records. The total number of babies born at the 26 hospitals during the study period was 72791 . Six babies met the criteria for ECMO, an incidence of $0.08 / 1000$ live births a year.
One further case might have been included: that of a baby with congenital diaphragmatic hernia in whom satisfactory oxygenation was never achieved $\left(\mathrm{PaO}_{2}\right.$ $1.36-3.01 \mathrm{kPa}$ ). At postmortem examination, severe pulmonary hypoplasia was found with a combined lung weight of $10 \mathrm{~g}$.

These data need to be confirmed, but they suggest that the need for ECMO for the newborn in England and Wales may be estimated at the present to be in the order of $50-60$ babies annually.

RODNEY RIVERS

Thames Regional Perinatal Group

ANDREW R WILKINSON

Oxford Regional Neonatal Intensive Care Advisory Committee

\section{Doppler and fetal growth retardation}

EDITOR,-In their review, Beattie and Whittle urge caution in the use of Doppler studies in managing a pregnancy complicated by intrauterine growth retardation (IUGR). ${ }^{1}$ While agreeing that Doppler studies should not be used in isolation to judge the timing of delivery, I am concerned that waning enthusiasm for Doppler studies on the part of obstetricians may mean that these studies are not performed at all in such pregnancies.

For the neonatologist, antenatal Doppler findings can be invaluable in identifying a group at high risk of necrotising enterocolitis. Both Hackett et al ${ }^{2}$ and Malcolm et al ${ }^{3}$ have demonstrated that the fetus with absent or reversed end diastolic flow in the aorta or umbilical artery is at significant risk (25-33\%) of developing necrotising enterocolitis. Postnatal Doppler studies have demonstrated that these babies have reduced velocity of blood flow in the superior mesenteric artery for at least the first week of postnatal life. ${ }^{4}$

If we are to reduce the rate of necrotising enterocolitis in this group, the neonatologist needs to be warned and enteral feeding delayed until the intestine has recovered from what may be an antenatal and a postnatal hypoxic-ischaemic insult. With delayed and careful introduction of expressed breast milk feeding, a number of us have found lower rates of necrotising enterocolitis than was originally reported.

STEVE KEMPLEY Royal London Hospital, Whitechapel,

1 Beattie RB, Whittle MJ. Doppler and fetal growth retardation. Arch Dis Child 1993; 69: 271-3. retardation. Overbeek T, Pearce JMF. Doppl verbek $T$, Pearce J fer. Deps the growth retarc neonatal necrotising enterocolitis, haemorrhage 94: 13-6.

3 Malcolm G Ellwood D, Devonald K, Beilby R, Henderson-Smart D. Absent or reversed end diastolic end flow velocity in the umbilical artery and necrotising enterocolitis. Arch Dis Child 1991; 66: 805-7.

4 Kempley ST, Gamsu HR, Vyas S, Nicolaides K. Effects of intrauterine growth retardation on postnatal visceral and cerebral blood flow velocity. Arch Dis Child 1991; 66: 115-8. 